Article

\title{
Key Criteria and Competences Defining the Sustainability of Start-Up Teams and Projects in the Incubation and Acceleration Phase
}

\author{
Monika Hudáková ${ }^{1}$, Hana Urbancová ${ }^{2, *}$ (i) and Lucie Vnoučková ${ }^{2}$ (1) \\ 1 Department of Management, Faculty of Economics and Management, Slovak University of Agriculture in \\ Nitra, Trieda Andreja Hlinku 609/2, 94976 Nitra-Chrenová, Slovak; monika.hudakova@uniag.sk \\ 2 Department of Human Resources and Department of Management, University of Economics and \\ Management, Nárožní 2600/9a, 15800 Prague, Czech Republic; lucie.vnouckova@vsem.cz \\ * Correspondence: hana.urbancova@vsem.cz
}

Received: 21 October 2019; Accepted: 23 November 2019; Published: 27 November 2019

\begin{abstract}
This study investigates and identifies crucial and efficient competencies of start-up founders and new business leaders, together with the identification of crucial support provided by accelerator programs. These competencies are necessary as individuals and businesses increasingly focus on innovations, industry 4.0, and technologies. This requires an innovative set of entrepreneurs' competencies to move businesses to the next level. The study gathered data by means of a quantitative questionnaire research and interviews conducted among start-up projects in accelerator programs over the past three years (2017-2019). In total, 158 start-ups were surveyed, and 38 successful teams were interviewed during this period. To analyze results, content analysis was used and Pearson's chi-square test and the association test were employed using descriptive and two-dimensional statistics tools. The results identified key success criteria and competencies of successful start-up teams. These include knowledge of the ecosystem, resource planning and use, an ability to move from the initial stages, awareness of communication methods, and lobbying. Our findings are that key activities leading to the acceleration of projects are raising awareness among the target group, furthering the development of contacts, facilitating more efficient use of resources, and enabling the identification of barriers to the next phase of development and ways to remove them. The results may inspire other researchers to conduct studies under other conditions to further identify and understand these entrepreneurial competencies.
\end{abstract}

Keywords: evaluation; entrepreneurship; start-up; young business; criteria; development; competence; team

\section{Introduction}

With the development of the global economy, the importance of human capital, which embodies the central asset of many businesses, is becoming the crucial criterion of success or survival [1]. The character of innovative human capital predestines it to be an indispensable accelerator of a company's long-term sustainability. Taking into account the development of human capital, it is important to realize that this is a milestone for today's business management, because the creation of the value of a company, and thus the future success is created by the application of knowledge of human capital and capital itself [2-5]. Hence, there is a focus on understanding entrepreneurial human characteristics and competencies.

Entrepreneurship competence refers to the ability to exploit opportunities and ideas to create value for others based on creativity, critical thinking, problem solving, initiative, perseverance, and the ability 
to work with others to plan and manage projects that have cultural, social, or commercial value [6]. Entrepreneurship education encompasses all learning tools and methods to strengthen entrepreneurship competences based on entrepreneurial approaches, practices, knowledge and skills [6,7].

This study aims to evaluate entrepreneurs working in an incubator and accelerator program of start-ups in the Czech Republic. Since the inception of this program in 2017, seven of 14 projects have been successfully developed and have gone from incubation and acceleration to growth. A total of 23 teams were involved in the second year, 2018, and 10 of them received support for their further development. However, most of the other projects have continued to develop because they received training, mentorship, networking benefits, and sources of funding. In 2019, 22 teams successfully finished the incubation phase and started their acceleration. This was the environment that was used to assess entrepreneurial competencies. This paper consists of six logically connected parts which includes an introduction, theoretical background of the work, material and methods, results, and discussion. The conclusion summarizes the research, its implications, and limitations.

\section{Theoretical Background of the Work}

Human capital is one of the key factors of organization's competitiveness. Every organization, even emerging start-ups, must ensure that their managers and employees have the right set of skills and competencies to guide the development of the organization. Competences can reveal differences between average and excellent managers and leaders [8]. In order for managers to achieve the desired results, it is essential that they have the competencies commensurate with the requirements of the job requirements [9-11]. In other words, competences are a combination of explicit knowledge, behavior, and skills of an individual, which provides him/her with the potential to successfully achieve various tasks [12]. Human capital generally represents hidden potential that may not be observed externally, but it is highly desirable for organizations to be able to share and exploit that potential $[13,14]$.

Organizations in all stages of their existence must place emphasis on the continuous development of these key employee competencies in order to succeed in today's turbulent and highly competitive market [14-16]. However, competences also indicate the ability to perform an activity in an effective manner, as well as to complete this activity within a specified time and under budget. They also indicate the ability to act in a flexible way in response to ever-changing environmental conditions. Focusing on goals, effort, and flexibility are some of the important outcomes of start-up founders having ideas, but not always the ability to develop and implement them and achieve success [14,17]. Additionally, competences need to be constantly improved upon and developed. In all organizations, whether they are start-ups or already established organizations, it is necessary to carry out educational activities and training to help answer the question of whether the desired goal, i.e., acquiring required competences, has been achieved.

As research indicates, start-up entrepreneurs tend to have innovative ideas but they often lack a clear strategy as to what product or service they will provide, and/or what they will capitalize on [18]. In most cases, they lack the necessary funds to pay for legal services or to correctly evaluate market conditions [19]. As a result, this very often leads to stagnation of the business. However, start-ups are often assisted by commercial projects which aim to assist their development, as well as to provide the individuals working on these projects with development of their competencies. For these start-up programs, also known as incubators, the focus is on developing key competencies that are important for the functioning of the business and for achieving success [20,21]. It is necessary to realize that being competent does not mean that the manager/leader/owner knows how to do everything, but rather that he/she knows what to do and how to do it. Reference [22] indicates that the most important drivers of sustainable entrepreneurship are behavioral factors and business factors. Research from the Czech Republic shows that innovativeness and development have become one of the greatest competitive advantages for all organizations. Human resources and their development are the main sources of creativity as well as new ideas, innovation, and skills, which was confirmed by the results of references $[23,24]$. Other results in the Czech Republic show that it is necessary 
to increase awareness of the existence of incubators or accelerators, especially in higher education facilities. According to reference [25], the priority areas for incubators are management, aid with business models, and strategies, and their main aim is to help lead start-ups to success. Therefore, this topic is very important in every economy around the world, especially for economies that have transitioned to a free market based system.

\section{Materials and Methods}

Since inception of incubator researched in this paper, evaluation has been carried out regularly during all of the years of the project, involving both new and existing teams and both quantitative and qualitative research. The basis for the project evaluation has primarily been qualitative methods (interviews, focus groups, case studies) and questionnaire surveying. The questionnaire used qualitative scales with scales set from 0 , meaning no competence, no shift, no knowledge, and no change, up to 5 representing high competences, a fundamental shift, overall change, and getting a new perspective. All participants completed both instruments. Ongoing telephone interviews have been used involving semi-structured interviews for continuous feedback, semi-structured interviews with researchers, and questionnaires with open questions for communication with deaf people (some projects are carried out by deaf entrepreneurs). Each start-up project in the incubation and acceleration phase was individually monitored, and progress and changes in development has been recorded together with the participants' subjective evaluation based on interviews and survey results for each project.

All 158 teams were analyzed based on their written project and application. All teams were also part of the first questioning regarding the education program evaluation and evaluation of the first phase of incubation. All of the teams also periodically participated in a part of the survey, which takes place three times a year, to monitor the progress of teams. This compulsory evaluation for the prospective five years was part of a contract that all of the teams signed in the beginning of the program. Further evaluation was conducted on the teams deemed to be most successful based on evaluation, and team activities and development. Altogether, 38 teams have been closely monitored and interviewed three times per year, because those teams successfully moved from the incubation phase to the acceleration phase and then to the development phase. Case studies have been created in collaboration with those teams to identify and share best practices within the incubator community. In all cases, a team leader was filling in the surveys or questionnaires, or participated in interviews and focus groups. The team leader, usually the company owner and founder, was tied to the continuing research linked to the signed contract between the project (young company-start-up) and the accelerator program, which included evaluation as a compulsory part of the process.

The combination of completed activities, interviews, document evaluation by means of content analysis, and the resulting scales and subjective evaluation has been achieved by data triangulation. Because all evaluations have been conducted three times a year, it is possible to demonstrate the benefits of the start-up accelerator program and the intervention for the subject.

\subsection{Research Design}

This study uses a qualitative correlational research design using a questionnaires and interviews to gather data. This survey design was selected based on [26] international methodologies such as I-DEV International: Measuring Value Created by Impact Incubators and Accelerators [27], or methodologies created by the project SIMPACT [28].

This primary research was carried out using questionnaires, interviews, and evaluation of written materials, while quantitative content analysis of the applications was used during each year. Projects involved in developing technology with social impacts were accepted. Applications were sent to the incubator in the first year during November 2017, in the second year during October 2018, and in third year from July 2019. Projects from all over the Czech Republic were accepted. The total number of applications which met the project requirements and were selected for support were 17 out 
of 56 applications in the first year, 22 in the second year out of 111, and 26 in the third year out of 130 applications (see Table 1). The teams had between 1 and 14 members.

Table 1. The number of projects per phase.

\begin{tabular}{cccc}
\hline Phase & 1st Year & 2nd Year & 3rd Year \\
\hline Incubation & 0 & 1 & 1 \\
Acceleration & 10 & 11 & 25 \\
Grow & 7 & 10 & 0 \\
\hline
\end{tabular}

Source: Application the authors' research.

The construct reliability was tested and validated by the Cronbach's Alpha coefficient in line with reference [29], and followed the recommendation that the value must be greater than 0.7. The Cronbach's Alpha coefficient was calculated using the SPSS software program. The value of the coefficient was higher than 0.8 , which is a high level and the construct therefore can be considered as being reliable. This research refers to an in-depth, detailed study of individual projects, resulting in a narrative description of behavior or experience in start-ups project and teams. It must be stated that this research is not used for generalizing or making predictions, instead the emphasis in this research is on exploration and the description of a phenomenon.

The results of the various projects have also been compared to their progress to the next stage to determine the areas that are decisive for the project progress. So far, seven teams from the first year and ten from the second year have successfully progressed from the incubation phase to the acceleration and growth phases. The teams from the third year are still in their early stages.

During the periodic evaluation, two questionnaires were used: (1) the incubation evaluation and (2) the acceleration evaluation. The first questionnaire contained 11 questions, which five were open, and the rest used the Likert scale-type multiple choice questions which represented the level of project development and satisfaction. The second questionnaire also contained both three open questions, multiple choice rating questions, and questions on financial, social, and economic impacts of each project.

The following scales were used to identify each start-up's development phase:

0 -No development

1-Obtaining information for development, passive receiving of business education

2-Initiative in information gathering, independent orientation, and knowledge of databases, resources, and contacts that can be used for team development

3-Knowledge of the issue, seeking experts and mentors as part of acceleration

4-Development of ability to make contacts and actively using mentor counselling

5-Growth and scaling, utilizing the ability to use mentorship for new/innovative practices.

The scales reflected the following areas: financial, personnel, supportive, managerial, marketing, process, social, environmental, and performance. The quantitative analysis focused on the evaluation of business results, financial sustainability, social impact, business development, and the impact of supporting activities of the accelerator program.

\subsection{Evaluation by the Content Analysis of Documents}

The content analysis of documents was used to assess the progress and development of each start-up [30]. Content analysis is a research technique for making replicable and valid inferences from texts or other meaningful matter. Researchers have [31] added four steps for case study research: (i) definition of the theoretical background, (ii) case planning, (iii) data collection, and (iv) results analysis and discussion. The quantitative content analysis in this study was used because this method detects aspects of the text that are not obvious in the amount of information available at first sight. The procedure of the performed quantitative content analysis reflected the summarized steps of reference [29] with partial adjustments according to the research context. First, all team applications 
and documents were read and statistically researchable elements were defined, i.e., words, phrases, or other parts of text with similar meanings, and classified into categories. Units of analysis were also defined; the units were repeatedly referred to in the majority of terms, or in all documents concerning the focus of the project, the basis for its elaboration, the justification of its viability, and its positive impact on the target groups. The terms were studied as units (in a certain context), but attention was also paid to their individual components (words), and phrases. The categories were created while reading the applications and the selected qualitative variables were observed, while primarily nouns (synonyms were merged under the same category) or their logical clusters were recorded. Altogether, 38 categories of qualitative variables were evaluated. All observed selected qualitative categories are listed in the Table 2 below.

Table 2. Observed selected qualitative categories.

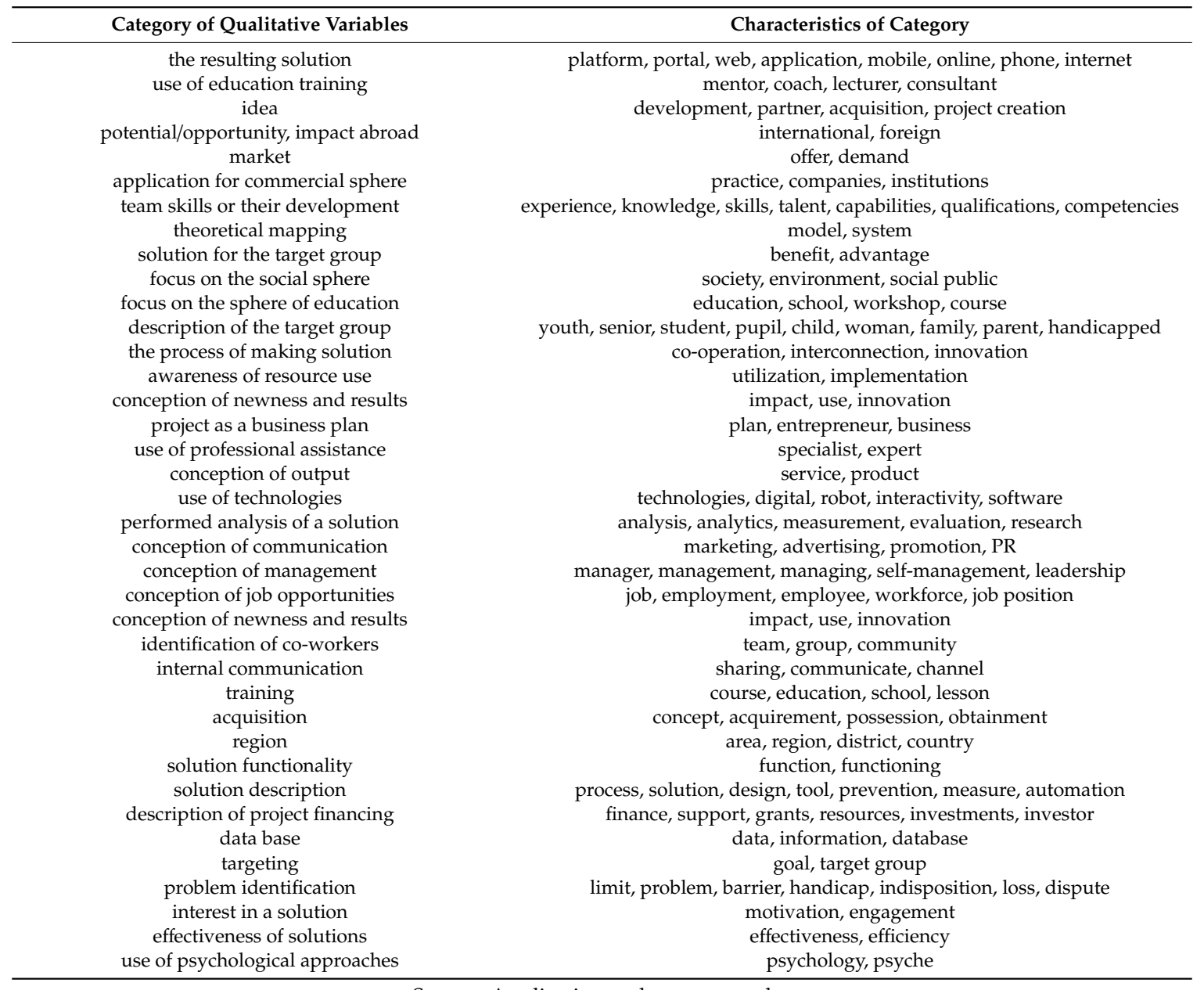

Source: Application and own research.

As was already mentioned, in some cases, where it was appropriate, second- and third-level categories were also created, and they further extended the main categories. This included the entire research problem, the reduction of a large amount of data, and elimination of the less important data, which facilitated their interpretation. In order to create a qualification system, the nominal quantification was chosen to monitor the frequency of occurrence of individual units in each category. Subcategories were then grouped under the main categories and the number of occurrences was recorded for each category. The results obtained by this method were further evaluated and processed. All primary data were firstly summarized, secondly processed in tables, and thirdly evaluated using descriptive and two-dimensional statistics tools. The average, minimum, maximum, standard deviation, and $\chi^{2}$ test were used to find the differences between the use of criteria for advancing and non-advancing 
projects. All project characteristics were tested between advancing and non-advancing projects. The occurrence of the characteristics in advancing projects compared to non-advancing projects was tested. Statistical significant differences $(\mathrm{p}<0.005)$ were found in the following criteria: mentor, coach, lecturer, consultant; model, system; young, old, senior, student, pupil, child, woman, family, parents, homeless, handicapped, disadvantaged; utilization, application, implementation; impact, application, innovation; technology, digital, robots, interactivity; analysis, measurement, evaluation, research; marketing, advertising, promotion, PR; manager, management, self-management, leadership; function, functioning; motivation, engagement; efficiency, effectiveness; and psychology, psyche.

\subsection{Qualitative Research}

The qualitative data were collected through interviews. Both semi-structured interviews with prepared questions and unstructured interviews were used for a deeper insight into the issue, which could not be clearly defined when designing the questions, and the solved areas could become apparent during the questioning and project solving. The subjects were also asked in the group interviews to evaluate the social impact and possibly other areas that may appear to be appropriate when discussing and evaluating their projects.

Based on the interviews conducted, the case studies were created for each team/project that suitably illustrated the development within the accelerator program. Typical projects with a significant change were selected for the case studies and were described in more detail (including a scenario of functional conditions for the given project, or limiting conditions and conditions that could be generalized for other projects). For this area of measurement, the MSC method was used, where interviews with participants define the areas and tools which they consider to be important for the success of their project.

\section{Results}

The results of the project and team development in the accelerator program are reviewed below, with summary results of the whole three years of the study period of this accelerator program (2017-2019). The partial results are discussed in the individual section based on the development actions and individual phases of the projects.

\subsection{Results of the Content Analysis}

There are differences between the occurrence of criteria for advancing and non-advancing projects in all three years of project monitoring. Table 3 shows characteristics of the evaluated categories. Names of the categories were shortened to fit the table.

Table 3. Characteristics of statistically significant categories.

\begin{tabular}{ccccccc}
\hline & AVG & MOD & MED & MIN & MAX & STD \\
\hline No of team members & 4.29 & 4 & 4 & 1 & 14 & 3.21 \\
Technology & 15.39 & 4 & 13 & 1 & 57 & 13.10 \\
Mentor, consultant & 3.14 & 1 & 1 & 0 & 24 & 5.25 \\
Development & 3.50 & 0 & 1.5 & 0 & 21 & 4.69 \\
Partner & 2.04 & 0 & 1 & 0 & 13 & 3.06 \\
Acquisition & 1.89 & 0 & 1 & 0 & 12 & 3.15 \\
Idea & 1.46 & 1 & 1 & 0 & 6 & 1.55 \\
Potential, opportunity & 2.07 & 1 & 1 & 0 & 10 & 2.31 \\
International & 1.82 & 0 & 1 & 0 & 9 & 2.33 \\
Market, offer, demand & 5.25 & 0 & 4.5 & 0 & 24 & 5.59 \\
Practices & 6.32 & 0 & 2 & 0 & 54 & 11.39 \\
Experience, knowledge, skill & 8.43 & 1 & 7 & 0 & 33 & 8.74 \\
Region & 0.89 & 0 & 0 & 0 & 7 & 1.52 \\
Model, system & 1.89 & 1 & 1 & 0 & 8 & 1.93 \\
\hline
\end{tabular}


Table 3. Cont.

\begin{tabular}{ccccccc}
\hline & AVG & MOD & MED & MIN & MAX & STD \\
\hline Benefit, advantage & 2.46 & 2 & 2 & 0 & 8 & 1.88 \\
Society, environment, social & 9.86 & 2 & 9 & 0 & 43 & 8.59 \\
Education, school, course & 9.89 & 0 & 3.5 & 0 & 69 & 14.72 \\
Senior, student, woman, etc. & 14.46 & 1 & 7 & 0 & 55 & 16.74 \\
Cooperation, interconnection & 6.82 & 4 & 5 & 0 & 17 & 5.33 \\
Use, implementation & 2.96 & 2 & 2 & 0 & 9 & 2.53 \\
Impact, innovation & 2.82 & 0 & 2 & 0 & 10 & 2.86 \\
Entrepreneur, business & 2.25 & 0 & 1 & 0 & 20 & 4.10 \\
Specialist, expert & 2.64 & 0 & 2 & 0 & 13 & 3.09 \\
Service, product & 4.00 & 1 & 2.5 & 0 & 15 & 3.95 \\
Analysis, research & 3.07 & 0 & 1.5 & 0 & 19 & 4.84 \\
Marketing & 3.68 & 4 & 2 & 0 & 23 & 4.62 \\
Management & 2.89 & 0 & 1 & 0 & 16 & 4.59 \\
Communication & 1.96 & 0 & 1 & 0 & 14 & 3.06 \\
Employment & 5.68 & 2 & 3.5 & 0 & 20 & 5.45 \\
Team, community & 5.25 & 1 & 4 & 0 & 18 & 4.49 \\
Function, functioning & 1.96 & 0 & 1 & 0 & 8 & 2.17 \\
Process, solution & 8.57 & 6 & 6 & 0 & 68 & 12.88 \\
Finance, investments & 8.00 & 5 & 6 & 0 & 31 & 6.13 \\
Data, information & 4.29 & 2 & 3 & 0 & 16 & 3.91 \\
Goal, target group & 5.14 & 1 & 5 & 0 & 11 & 3.58 \\
Limit, problem, handicap & 6.04 & 0 & 2 & 0 & 75 & 14.12 \\
Motivation, engagement & 1.04 & 0 & 1 & 0 & 4 & 1.29 \\
Efficiency, effectiveness & 1.75 & 0 & 0.5 & 0 & 9 & 2.63 \\
Psychology & 0.86 & 0 & 0 & 0 & 6 & 1.53 \\
\hline
\end{tabular}

Source: Application and own research

Based on this evaluation, all 38 categories of qualitative variables (plus one showing the number of projects) were evaluated. The progressive projects used some criteria in all cases, while the non-progressive projects have omitted them. This resulted in insufficient sophistication and preparedness of a project, showed an insufficient impact on the target group, or occurred as a result of a project's lower or problematic feasibility.

When testing whether there were statistically significant differences in the use of the accelerated and the non-progressive projects in the use of the monitored quality criteria, the Chi-square test confirmed the statistically significant differences between the two groups $(p=0.000)$, where the power of dependency is 0.426 .

Projects that advanced to the acceleration phase were more likely to use all of the monitored criteria in their project preparation; the criteria use was more frequent, and all of these criteria were used. Projects that did not proceed did not use all of the criteria or did not deal with them. As the incidence rates varied considerably in some criteria, the criteria were subjected to further testing. Specifically, statistically significant differences were found in the following criteria (all of them were $p=0.000$ ): the use of training (involving a mentor, coach, lecturer, or consultant), the development process, the partner, the theoretical mapping (model, system), the international dimension of the project, the target group focus (young, old, senior, student, pupil, child, woman, family, parents, homeless, handicapped, or disadvantaged), the grasping of the project idea, project application (utilization, application, and implementation), the emphasis on the project impact (impact, application, and innovation), the use of professional assistance (specialist, expert), the use of technologies (technology, digital, robots, and interactivity), the processed analyses (analysis, measurement, evaluation, and research), the marketing awareness (marketing, advertising, promotion, public relations (PR)), the concept of project management (manager, management, self-management, and leadership), the communication within the project internally and externally, the solution functionality (function, functioning), the interest 
in a solution (motivation, engagement), the solution effectiveness (efficiency, effectiveness), and the use of psychological approaches (psychology, psyche).

Overall, the results of the content analysis show which criteria are essential and distinguish the successful projects from the unsuccessful ones. It is evident that some projects are more sophisticated, and thus are even more different to the less successful ones. In the light of the points mentioned above, it can be summarized that education and counselling, support for innovation, cooperation, social benefits in the context of efficient management and the use of technology, and strengthening the development of monitoring and information systems should be a priority for all businesses, especially start-ups.

The results of the content analysis provided a basis for further evaluation activities as well as an evaluation of the initial state and motivation of projects for further development. The analysis was designed to set criteria to further evaluate the progress of projects, regarding the evaluation methodology and plan. The subsequent evaluation of the projects was based on the interconnection of the monitored criteria and their further development. Subsequently, the qualitative evaluation of the projects using interviews again emphasized the information on the shift in the sub-criteria, and the interviews proved to be important for the projects themselves.

The results of the analysis of documents can be evaluated as being suitable for the further implementation of projects, because if the projects met the partial criteria at the beginning, they had a significantly higher chance of subsequent successful development and involvement in both educational activities and independent development through mentoring and other activities, as well as of organizing their own team and creating value for investors. The evaluation of the projects allowed for the identification of successful entrepreneurial competencies.

\subsection{Impact of the Accelerator Program}

The evaluation of teams has shown a noticeable difference between the supported and unsupported projects. The supported projects are further developed and implemented, and also offer (at a minimum) new jobs and opportunities. The unsupported projects mostly suppressed or terminated their activities. In summary, project support makes sense, and the support teams have appropriately been selected and have a chance of further development.

The developing projects show a greater focus on target groups. Based on their experience, testing, and operations, they also already know how to adapt their products and services. Some projects continued in their originally set direction, which did not need to be revised, and experienced further success with their project, expanding their volume of users. However, the projects in the provisional stage have not been able, with a few exceptions, to generate sales, and hence to obtain a positive turnover. There are only a few exceptions, which generated some revenue, but in smaller volumes. Other projects are currently testing and are not yet in the commercial phase. Many projects also have basic services that are free of charge, through information portals or applications, which in turn will lead to the commercialization of specific revenue-generating services.

The number of users of start-up projects has been mostly low so far. Exceptions can be seen in some of the projects that have already offered their services through a website with up to 18,000 unique users per month, some services are paid, while others are unpaid. A notable exception has been projects for the deaf, which involve communication with about 1500 deaf people. There are no users of the unsupported projects, and those projects are no longer active.

The leaders of the supported projects evaluated their development to the present stage as being moderately advanced at a 2 , on the scale where 0 is no shift and 5 means fully successful in practice/on the market. The unsupported projects have defined their value as being 0 . Project leaders have evaluated the efficiency of their resource allocation in the same way. The supported projects obtained a value of 2, while the unsupported ones obtained a 0 . A significant shift was recorded by the supported projects in the level of project benefits for customers/target groups. The supported projects received a value of 5 , which is the highest value, representing clear usage by the target group. On the other hand, 
the unsupported projects received a value of 0 . In this area, the significant shift, benefit, and support of target groups can be observed. The project sustainability was again rated at 2 out of 5 by the supported projects and 0 by the unsupported projects. When evaluating the accelerator's support, both the supported and unsupported projects rated it as a 3 out of 5 (one project leader even gave it a 5 rating), i.e., the usability and suitability of the provided program was perceived to be high regardless of whether a project was supported by it or not. The educational activities undertaken by the participants are important either for current projects or for the future, as the awareness of entrepreneurial activities among the public is increasing.

Based on the summary of the regular evaluation results, it can be stated that the projects have been developed primarily in management, marketing, and processes, while the most beneficial activities for the project teams were individual mentoring, followed by lectures. Further details are provided in Table 4.

Table 4. Project development areas (from 26 projects, 18 were supported, and 8 were not supported, all were in the acceleration or growth phase).

\begin{tabular}{ccccc}
\hline & AVG & MOD & MED & STD \\
\hline Financial & 2.8 & 3 & 3 & 1.32 \\
Human resources & 3.75 & 4 & 4 & 1.02 \\
Communication & 3.95 & 4 & 4 & 0.76 \\
Management & 3.85 & 4 & 4 & 0.81 \\
Marketing & 3.8 & 4 & 4 & 1.24 \\
Process & 3.65 & 3 & 3 & 0.93 \\
Social & 3.75 & 4 & 4 & 1.16 \\
Environmental & 2.55 & 3 & 3 & 1.43 \\
Performance & 3.65 & 3 & 4 & 0.93 \\
\hline
\end{tabular}

The teams positively evaluated the quality of mentors, especially the individual approach, which involved focusing on the topic in depth with great enthusiasm. Team leaders characterized the approach of mentors as follows: "The best was mentoring, concretely [name of the mentor]."; "Individual consultation with mentor was the most important for us, [it] moved the team forward."; "Mentoring helped us with our real issues."; "We could ask [the] mentor when we were stuck in some phase, that was great."; "We still [discuss] project progress and development with [our] mentor and it moves us forward."

Because of the educational activities, the project teams have developed all the competences examined, a knowledge of the ecosystem, the resources required, and of good planning, the ability to move beyond the initial stages, an awareness of ways of communicating, and a lobbying ability. Most of all, there has been progress in knowledge of the ecosystem, and awareness of ways of communicating and lobbying.

The accelerator has helped the project teams primarily in raising awareness of change in the target group, the public, and public officials, as well as the development of contacts. The project teams most positively evaluated the follow-up care of mentors. It can be stated that the teams consider project development as being time consuming, but assess their gained experience, the high team support, the individual approach, and the quality feedback from mentors as being highly positive.

\subsection{Key Areas of Start-up Competency Development}

According to the analysis of the data of the study, it can be stated that the greatest development of competencies of the project teams has always been in the ecosystem knowledge, raising the awareness and the communication improvement, which in most cases was rated 4 on the given scale. Table 4 above provides additional details regarding this. In all of the years studied, the greatest problems were observed in the development of competencies in the area of having enough resources, where the unsupported projects mostly seemed to have not acquired this competence yet. A specific competence 
also involves the ability to identify and remove barriers that are not fully developed, but there were differences among the project teams, with some having not made any progress in this area at all, while others made great progress. However, it can be said that in all three years, the project teams involved positively evaluated the accelerator. The teams all positively evaluated their competence development, but also their clarification of target groups or their projects' possible modification based on pilot testing results and gradual further development of the project.

The overall assessment of the current state of projects has shown that the project teams are continuously working and perceive a shift that has occurred compared to the stage before joining the program, but have not still explicitly identified sustainability principles. The involved entities also gained an overview of the competition, got the opportunity to compare themselves with the others, and built on their existing domestic and foreign experience. The project teams developed primarily in the field of ecosystem knowledge, and in the ability to move beyond the early stages. Progress was also made in developing strong methods of communication, both external and internal, and acquiring contacts, leading to project teams demonstrating strong competencies in these areas. It can be assessed that at present, the project teams generally have the capacity to make contacts and are able to actively use and apply their mentors' advice.

The project teams consider awareness-raising among target groups, further development of contacts, more efficient use of resources, and identification of barriers to further development phases and their removal to be the key activities leading to project acceleration.

During the project evaluation, the project representatives were asked to give their subjective evaluation of the project success, project effectiveness, project benefits for customers/target groups, project sustainability, and an overall evaluation of coaches and mentors helping them to increase their competencies and boosting their successful product placement/services for their target group. The scale was $0-5$, where 0 means no shift/no improvement/no benefit, and 5 means being successful in practice/effective (see the methodology for more details). The results in each year are shown in Table 5 . In the third year, the projects which joined the program during that year were still in their early stages, and thus have not been included in Table 5 .

Table 5. Evaluation of the project development based on the accelerator activities (from 26 projects: 18 were supported, 8 were not supported, all were in the acceleration or growth phase).

\begin{tabular}{ccccccccc}
\hline & \multicolumn{4}{c}{ 1st Year } & \multicolumn{4}{c}{ 2nd Year } \\
\hline & AVG & MOD & MED & STD & AVG & MOD & MED & STD \\
Project success & 2.4 & 3 & 3 & 1.11 & 3.1 & 4 & 3 & 1.17 \\
Project efficiency & 2.6 & 3 & 3 & 1.51 & 3 & 3 & 3 & 1.72 \\
Benefit for target group/customers & 3 & 3 & 3 & 0.50 & 3.6 & 4 & 3 & 1.92 \\
Project sustainability & 1.5 & 2 & 2 & 1.12 & 2.125 & 2 & 2 & 1.60 \\
Support of coaches and mentors & 4 & 5 & 5 & 1.00 & 4.4 & 5 & 5 & 0.75 \\
\hline
\end{tabular}

The table shows that the greatest development has come about with the support of coaches and mentors, which was the competency to develop skills as an entrepreneur. This support has led mostly to the specification of products/services for target groups, but also in other areas. Furthermore, the quality of the team development has evidently been increasing based on the continuous evaluation of the accelerator program and implementation of changes, thus boosting the evaluation and development of the involved start-ups.

\subsection{Main Reasons of Start-up Failure}

The most frequently mentioned reasons for the failure of start-ups by the individual project team members are given below and range from the project team's ability to secure financial support to their ability to work as a team. It should be noted that some of the reasons are subjective, in particular, the complaints about the lack of financial support, which is not obligatory. 
The unsuccessful projects (21\%) which did not continue with project development and cancelled the whole effort or the company (or both) have stated that they were not feasible without financial support. Only 10 projects per year got financial support. But there were other projects developing without external financing, but still using community support, such as support from consultations, mentors, education, and online business courses.

The causes for failure that were mostly mentioned by unsuccessful teams were a lack of a clearly defined mission, vision, product/service, or target group, disappointment towards the project, a lack of cooperation, not enough time for project development, only training without practical support for development, and a low financial support of the projects from subsidies. Another problem was also a very busy program involving training and tasks. In contrast, according to the testimony of the project teams, a lack of attention was found in some corporations from investors. It was clear that for many of the projects that failed, their entrepreneurs had an inability to tackle these issues.

In terms of sustainability, it can be stated that the projects often needed investment, otherwise they would have been not be able to survive. Many projects were as start-ups when their members were employed; therefore, they could not be $100 \%$ monetized as a company, meaning options are limited compared to for larger companies, while their platforms need to be maintained and subsidized by other sources. Many projects, however, later wanted to come back to the project and cooperate with coaches.

\section{Discussion}

According to the results, it can be concluded that [22] that the most important drivers of sustainable entrepreneurship are behavioral factors and business factors. When entrepreneurs are equipped with competencies, they can take advantage of opportunities and their ideas to create value for others. The competencies are rooted in creativity, critical thinking and problem solving, initiative and perseverance, and the ability to work with others to plan and manage projects with a cultural, social, or commercial value [4,7]. Using the projects in the incubator, it was clear that for those deemed successful, the entrepreneurs developed competencies which allowed the acceleration of projects.

There are various methods and opportunities to transfer ideas into practice in personal, social, and professional activities, but it is necessary to emphasize how these contexts and opportunities arise. Individuals should know and understand approaches to project planning and management that include both procedures and resources [6], while also knowing their strengths and weaknesses that affect the success or failure of planned projects [1,5]. These are all competencies that are useful in project development and implementation.

Research has shown that entrepreneurial skills are based on creativity, which includes imagination, strategic thinking and problem-solving, and critical and constructive reflection within evolving creative processes and innovations, in line with the conclusions of reference [6]. When developing entrepreneurial competencies, it is necessary to focus on developing the ability to work both individually and with others in a team, mobilizing resources (people and things) and sustaining activities, including the ability to make financial decisions on costs and value. However, the ability to communicate and negotiate effectively with others and to deal with uncertainties and risks in making informed decisions is essential, as demonstrated by the evaluation results in this article. Although some projects already entered the accelerator with a product, it is still noticeable that the support within the accelerator led to greater activation, impact propagation, and project development.

Overall, the following can be recommended for the development of project teams:

1. The ability of teams to interconnect and share experience, to help each other in the community, to share contacts in the project community;

2. The selection of mentors with experience from their own start-ups they have built from scratch, involvement of personalities with experience in starting their own projects;

3. Increasing the time available to practice activities and tasks, obtain more background materials and workshops to develop their own plans; 
4. Creating efficient communication, avoiding excessive electronic communication, setting clear deadlines, maintaining a consistent form and quality of outputs, developing a more transparent schedule of support activities, including logical continuity; i.e., greater consistency of sub-activities;

5. Greater internationalization, to inform projects about possibilities for scaling outside the domestic market, as well as more information about business in an international environment;

6. More information to attract investors and links with investors, emphasis on the ability to present investor-relevant information;

7. Enhancing contacts and promoting lobbying;

8. Developing an individual approach and obtaining high quality feedback.

On the other hand, based on the interviews and analysis of documents, including business plans and project presentations, the project risks include, in particular, the following items:

1. A lack of time for training and development of competencies and of team members according to a set schedule;

2. A lack of time for team members overall, insufficient involvement of some team members in project development;

3. Unclear targeting and pricing strategies;

4. Failure to be sufficiently attractive to investors;

5. Inability to sufficiently identify the target group and appropriately estimate its needs, lack of an availability to market and communicate the start-up's solution, including an inability to lobby for the product to be accepted by the target group;

6. Lack of information and scalability capabilities;

7. Inability to manage the project team effectively;

8. Lower self-reflection and a change in thinking from the initial idea to the viable project.

It can be summarized that projects develop positively based on the support provided, especially by mentors and their support individually for the situation of the project. This is valid both for the projects that already have a final product or service, and for those that are still in the testing phase. Identifying the target group and the number of users is essential, such as by obtaining the awareness of the community, users, and investors. Moreover, networking and increasing the number of people involved in job creation are important.

The results of the analysis of documents with the help of the content analysis have shown that the projects can be assessed according to 17 criteria which were identified as the key ones for further project development and implementation. These are: use of training, development, partners, theoretical mapping, international dimensions of the project, focusing on the target group, grasp of the project's applications, emphasis on the project's impact, the use of professional assistance, use of technologies, the use of analyses for background project management, communication within and outside the project, functionality of the solution, interest in the solution, effectiveness of the solution, and the use of psychological approaches. The results of the content analysis have indicated which criteria are essential and distinguish the successful projects from the unsuccessful ones. It is possible to identify progressive projects and those that are not very likely to succeed.

It is important to focus on the development of competencies towards the practical application of knowledge in business and the increase in the volume of lessons devoted to the specific application of knowledge directly for the projects of participants. The need to assign experienced business mentors is indispensable.

According to reference [32], a friendlier context (fiscal, legal, organisational, etc.) and stronger support from the government, supply chain agents, and consumers are required as enablers for the successful implementation of sustainable business models. For example, research in Korea addressing the performance of manufacturing SMEs show highlighted the relevance of Government Assistance Programs to improving start-up and SMEs performances [33]. The results in the Czech Republic show 
that key success criteria ( $\mathrm{p}$-value $=0.000$ ) of successful start-ups are: use of education and training, development, partners, theoretical mapping, use of expert help, use of concrete technologies, knowledge of project management, project functionality, personal interest in project delivery, and efficiency of solutions [23], which are in accordance with reference [25].

We can suggest that educational and other institutions which focus on the support of start-ups project should focus on courses in the area of increasing the efficiency of a manager's work through correct planning, effective time usage, and development of the competencies of their teams through delegation. It is necessary to focus on the problem of self-management and life-management, which would contribute to the prevention of burnout and workaholic syndromes, and towards building a healthy lifestyle, which was confirmed by reference [25].

\section{Conclusions}

This study has identified the key competencies of successful start-up teams. These are as follows: knowledge of the ecosystem, planning and the use of enough resources, the ability to move beyond the initial start-up stages, awareness of ways of communication, and the ability to lobby. The key activities leading to the acceleration of projects are awareness-raising among the target group, further development of contacts, and more efficient use of resources and identification of barriers to further phases and their removal.

Based on the evaluation and identified shortcomings, it was necessary to develop a quality infrastructure that maintains and develops multiple projects in various phases. Based on that, the projects can be better communicated, the activities within the accelerator are more focused directly on the practice of projects in their current phases, and there is an individualized approach according to the project level and its focus. Most of all, project teams need their individual mentor services, which they also view as the most beneficial services. Involvement in an accelerator also creates greater publicity, relevance, goodwill, and reputations for investors and partners.

These results help to define key success criteria of start-ups and innovative entrepreneurships. The limits of this study cannot be ignored. The first one is subjectivity in selecting the individual definitions and categories used for the content analysis. The second one is the process of creating categories of analyzed document content and interviews, and assigning individual words or links to these categories.

The contribution of this article lies in the identification and evaluation of the success factors of young entrepreneurship. Furthermore, the practical contribution lies in the identification and evaluation of competencies and criteria for the sustainable development of social start-ups. The practical contribution lies in presenting the concrete results from the real start-up accelerator program and over 250 projects involved in this program. The results are important for the development of new start-up ideas and projects while their main efficient approaches are presented. In future research, the authors will focus on statistical tests to assess the differences between the results for the project development areas between the two types of projects identified (supported and not supported).

Author Contributions: All authors contributed equally to this paper.

Funding: This paper was created within the project VEGA “Integrated talent management model and its impact on economic results of enterprises" from The Ministry of Education, Science, Research and Sport of the Slovak Republic. Project registration number VEGA 1/0543/17.

Conflicts of Interest: The authors declare no conflict of interest. The funders had no role in the design of the study; in the collection, analyses, or interpretation of data; in the writing of the manuscript, or in the decision to publish the results. 


\section{References}

1. Claus, A.M.; Wiese, B.S. Development and test of a model of interdisciplinary competencies. Eur. J. Work Organ. Psychol. 2019, 28, 191-205. [CrossRef]

2. Dobrosavljevic, A.; Urosevic, S.; Astratova, G.V. Assessment of HR competencies in housing and communal utility services taking into account consumer perception. Upr. Manag. 2019, 10, 72-77. [CrossRef]

3. Khattak, M.S.; Mustafa, U. Management competencies, complexities and performance in engineering infrastructure projects of Pakistan. Eng. Constr. Archit. Manag. 2019, 26, 1321-1347. [CrossRef]

4. Otoo, F.N.K. Human resource management (HRM) practices and organizational performance. The mediating role of employee competencies. Empl. Relat. 2019, 41, 949-970. [CrossRef]

5. Potnuru, R.K.G.; Sahoo, C.K.; Sharma, R. Development and test of a model of interdisciplinary competencies; Team building, employee empowerment and employee competencies. Moderating role of organizational learning culture. Eur. J. Train. Dev. 2019, 43, 39-60. [CrossRef]

6. European Commision. The European Entrepreneurship Competence Framework (EntreComp). 2016. Available online: http://ec.europa.eu/social/main.jsp?catId=1317\&langId=en (accessed on 26 November 2019).

7. Zeng, G.T.; Xu, Y.H. Sustainable development and the rating effects: A strategic categorization approach. Corp. Soc. Responsib. Environ. Manag. 2019. [CrossRef]

8. Ahadzie, D.K.; Proverbs, D.G.; Olomolaiye, P. Towards developing competency-based measures for construction project managers: Should contextual behaviors be distinguished from task behaviors? Int. J. Proj. Manag. 2008, 26, 631-645. [CrossRef]

9. Muzzi, C.; Albertini, S. Communities and managerial competencies supporting SMEs innovation networking: A longitudinal case study. RED Manag. 2015, 45, 196-211. [CrossRef]

10. Biloslavo, R.; Bagnoli, C.; Figelj, R.R. Managing dualities for efficiency and effectiveness of organisations. Ind. Manag. Data Syst. 2013, 113, 423-442. [CrossRef]

11. Abraham, S.E.; Karns, L.A.; Shaw, K.; Mena, M.A. Managerial competencies and the managerial performance appraisal process. J. Manag. Dev. 2001, 20, 842-852. [CrossRef]

12. Wronka-Pospiech, M. The identification of skills and competencies for effective management in social enterprises. A managerial perspective. Manag.-Pol. 2016, 20, 40-57. [CrossRef]

13. Hitka, M.; Kozubikova, L.; Potkany, M. Education and Gender-Based Differences in Employee Motivation. J. Bus. Econ. Manag. 2018, 19, 80-95. [CrossRef]

14. Boyatzis, R.E. Competencies in the 21st century. J. Manag. Dev. 2008, 27, 5-12. [CrossRef]

15. Depra, V.M.; Pereira, D.G.; de Marchi, A. The contribution of informal organizational learning to the development of managerial competencies. Navus-Rev. Gest. E Tecnol. 2018, 8, 22-36. [CrossRef]

16. Verle, K.; Markic, M.; Kodric, B.; Zoran, A.G. Managerial competencies and organizational structures. Ind. Manag. Data Syst. 2014, 114, 922-935. [CrossRef]

17. Wisittigars, B.; Siengthai, S. Crisis leadership competencies: The facility management sector in Thailand. Facilities 2019, 37, 881-896. [CrossRef]

18. Amagoh, F. Leadership development and leadership effectiveness. Manag. Decis. 2009, 47, 989-999. [CrossRef]

19. Giraudo, E.; Giudici, G.; Grilli, L. Entrepreneurship policy and the financing of young innovative companies: Evidence from the Italian Startup Act. Res. Policy 2019, 48, 103801. [CrossRef]

20. Hasan, S.; Koning, R. Prior ties and the limits of peer effects on startup team performance. Strateg. Manag. J. 2019, 40, 1394-1416. [CrossRef]

21. Chatterji, A.; Delecourt, S.; Hasan, S.; Koning, R. When does advice impact startup performance? Strateg. Manag. J. 2019, 40, 331-356. [CrossRef]

22. Tur-Porcar, A.; Roig-Tierno, N.; Mestre, A.L. Factors Affecting Entrepreneurship and Business Sustainability. Sustainability 2018, 10, 452. [CrossRef]

23. Vnoučková, L. Criteria of Innovativeness and Creativity in Start-Ups and Innovative Entrepreneurship. Qual. Innov. Prosper./Kvalita Inovácia Prosper. 2018, 22, 27-43. [CrossRef]

24. Vnoučková, L.; Urbancová, H. Current success criteria of socially-oriented start-ups in incubation stage. In Proceedings of the 6th International Conference Innovation Management, Entrepreneurship and Sustainability (IMES 2018), Praha, Oeconomica, 31 May-1 June 2018; University of Economics: Praha, Oeconomica, 2018; pp. 1096-1104, ISBN 978-8-02-452274-6. [CrossRef] 
25. Smolová, H.; Kubová, P.; Urbancová, H. Success Factors for Start-ups Related to Agriculture, Food and Nutrition and Their Relevance to Education. Acta Univ. Agric. Silvic. Mendel. Brun. 2018, 66, 791-801.

26. De Vaus, D. Surveys in Social Research; Routledge/Taylor and Francis: London, UK, 2002.

27. I-DEV-ANDE-Incubator-Report-Measuring-Value-Created. Available online: http://idevinternational.com/ wp-content/uploads/2016/01/I-DEV-ANDE-Incubator-Report-Measuring-Value-Created-11-14.pdf (accessed on 26 November 2019).

28. Simpact Project. Available online: http://www.simpact-project.eu/ (accessed on 26 November 2019).

29. Disman, M. Jakse Vyrábí Sociologická Znalost: Příručka pro Uživatele, 4th ed.; Karolinum: Prague, Czech Republic, 2011; Volume 372, ISBN 978-8-02-461966-8.

30. Krippendorff, K. Content Analysis: An Introduction to Its Methodology, 2nd ed.; Sage Publications: Thousand Oaks, CA, USA, 2004; Volume 18.

31. Yin, R.K. Case Study Research Design and Methods, 5th ed.; SAGE Publications: Thousand Oaks, CA, USA, 2014.

32. Fonseca, L.M.; Domingues, J.P.; Pereira, M.T.; Martins, F.F.; Zimon, D. Assessment of Circular Economy within Portuguese Organizations. Sustainability 2018, 10, 2521. [CrossRef]

33. Han, J.H.; Park, H.-Y. Sustaining Small Exporters' Performance: Capturing Heterogeneous Effects of Government Export Assistance Programs on Global Value Chain Informedness. Sustainability 2019, 11, 2380. [CrossRef]

(C) 2019 by the authors. Licensee MDPI, Basel, Switzerland. This article is an open access article distributed under the terms and conditions of the Creative Commons Attribution (CC BY) license (http://creativecommons.org/licenses/by/4.0/). 